\title{
REPENSANDO O ESPAÇO PÚBLICO EM TEMPOS DE PANDEMIA: Hannah Arendt, 60 anos depois de A condição humana
}

\author{
Renata Nagamine* \\ Denise Vitale**
}

\begin{abstract}
Este ensaio reflete sobre a ideia de espaço público no pensamento de Hannah Arendt, tal como apresentada em A condição humana, elaborando sobre a pandemia de Covid-19, ocorrida no ano de 2020. O artigo a toma como uma experiência que nos convida a pensar as reconfigurações do espaço (e do tempo) olhando para o esvaziamento das cidades, a paralisação da economia, a circulação de notícias falsas e o revigoramento de certas formas de interação. Entendemos que Arendt nos fornece elementos para pensar os desafios postos pela pandemia.
\end{abstract}

Palavras-chave: Vida Ativa. Espaço Público. Pluralidade. Pandemia. Teoria Política.

\section{INTRODUÇÃO}

Este ensaio propõe pensar o espaço público, tal como concebido por Hannah Arendt em seu livro A condição humana, elaborando sobre a experiência da pandemia de Covid-19, que compreende desde as medidas quarentenárias ao luto por mortes em massa. O exercício se justifica, a nosso ver, porque a pandemia, ainda presente entre nós, é uma experiência liminar: lança-nos em um espaço e tempo intermediários, que podemos descrever com Hannah Arendt $(2016$; 1994a) como um hiato entre um mundo que não é mais e outro que não é ainda. Tomada como tal, a pandemia teria instaurado um tempo denso, com a interrupção do curso de um tempo homogêneo. Nós, modernos, relutantes ou não, tendemos a ter

* Universidade Federal da Bahia. Instituto de Humanidades, Artes e Ciências Professor Milton Santos.

Avenida Barão de Jeremoabo s/n, campus Ondina (Paf V). Cep: 40170115. Salvador - Bahia - Brasil. renagamine@gmail.com

https://orcid.org/0000-0003-2447-5548

* * Universidade Federal da Bahia. Instituto de Humanidades, Artes e Ciências prof. Milton Santos. Programa de Pós-Graduação em Relações Internacionais.

Avenida Barão de Jeremoabo s/n, campus Ondina (Paf V).

Cep: 40170115. Salvador - Bahia - Brasil.

denise,vitale@ufba.br

https://orcid.org/0000-0002-0777-3642 menos sensibilidade para as texturas do tempo, mas Arendt, que errava pelo mundo dos gregos antigos, conhecia bem o chronos e o kairós, o tempo do calendário e o tempo oportuno.

Entendemos que a compreensão da experiência da pandemia requer um olhar crítico para ideias e práticas da modernidade, como aquele que Arendt lança para ela em $A$ condição humana. Neste livro, Arendt reflete sobre a transformação da manutenção da vida como ocupação de primeira ordem e se debruça sobre seus efeitos na política. Pensamos que a pandemia, uma experiência compartilhada de paralisação da economia e retirada dos espaços de circulação, encontro e deliberação, por força de um vírus que reinsere a morte na vida, explicita os desafios de um mundo cada vez mais complexo, marcado pelo consumismo, a destruição do meio ambiente, a desigualdade crescente, o ressurgimento do autoritarismo sob vestes populistas, o esvaziamento físico dos espaços e a importância crescente das mídias sociais. O pensamento de Hannah Arendt pode ser útil para pensar esses desafios.

O presente ensaio pretende pensar a noção arendtiana de espaço público sessenta 
anos depois de sua formulação em $A$ condição humana. No âmbito teórico, analisaremos como Arendt formula sua ideia de espaço público. Para iluminar por contraste a construção de Arendt, apresentaremos aspectos de como Jürgen Habermas concebe a esfera pública, o que é pertinente porque as noções arendtianas de espaço público, ação e comunicação influenciaram seu pensamento, que a seu turno se tornou referência quando se trata do conceito. Pela atualidade do pensamento de Arendt, as interpelações que a experiência da pandemia nos coloca, e a importância da formulação arendtiana para teóricos contemporâneos, o artigo se deterá inicialmente em um esforço conceitual por deixar ver o que Arendt entende por espaço público e por distingui-lo do que Habermas entende por esfera pública.

Feita essa reconstrução inicial da categoria, elaboraremos sobre a experiência pandêmica, no intuito de pensar como as interações e, com elas, os espaços se reconfiguram em função das medidas quarentenárias que a pandemia requer adotar. Sabemos que é arriscado elaborar a partir da experiência, e ainda mais em seu calor, mas assumimos o risco considerando que esse tipo de prática intelectual está no cerne do método arendtiano (Vollrath; Fantel, 1977). Para tanto, recorreremos à nossa própria vivência da pandemia - àquilo que vimos e ouvimos em nossos círculos e em mídias sociais, mais especificamente o Twitter - e a matérias de jornais, 올 sites e vídeos, que em alguma medida lhe conferem uma dimensão compartilhada. de espaço público em $A$ condição humana, i buscando recuperar seus elementos mais cen$\dot{2}$ trais no pensamento arendtiano. Na sequênळ cia, pensaremos a experiência contemporânea

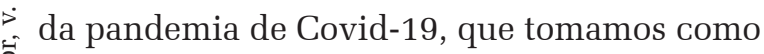
uma experiência liminar, ou seja, de transição entre um mundo que não é mais, e outro que não é ainda, e para o qual procuramos olhar com lentes arendtianas. Por fim, apresentamos algumas ilações, à guisa de conclusão.

\section{O ESPAÇO PÚBLICO EM A CONDI- ÇÃO HUMANA: um esforço conceitual}

Encontramos algumas linhas gerais da concepção arendtiana de espaço público na última seção das Origens do totalitarismo, na qual Arendt se dedica a pensar a relação entre totalitarismo e ideologia, espontaneidade, igualdade e liberdade. Arendt desfiará tais relações em A condição humana, cuja primeira edição é de 1958. Neste livro, ela se propõe a pensar "o que estamos fazendo" e articula seu pensamento em torno do que chama de atividades da vida ativa, em contraste com a vida contemplativa, em que se centra o que ela denomina de tradição filosófica. Vida ativa e vida contemplativa não se contrapõem para Arendt, que as articula, por exemplo, em sua reflexão sobre o entendimento (1994b). A distinção no livro está ligada à sua pretensão de pensar a condição humana no mundo: é de aspectos desta condição que ela pretende que a categoria "vida ativa" dê conta.

De partida, Arendt nomeia as atividades que são próprias da vida ativa, a saber, o trabalho, a obra e a ação, associando cada uma a um espaço. Por conta dessa associação, Seyla Benhabib (2003) fala em "topologia da vida ativa" quando reflete sobre o espaço público. Façamos uma primeira abordagem delas. Sucintamente, o trabalho corresponde ao aspecto biológico da vida humana, que para Arendt (1998) compreende as necessidades vitais e a reprodução da espécie. Essas atividades seriam próprias do espaço privado. Já a obra corresponde à dimensão mundana da vida humana na terra, à capacidade dos seres humanos de erigir edifícios, fabricar artefatos mais duráveis que a vida individual, construir instituições e urdir histórias. A ação corresponde, enfim, à política e está associada à pluralidade, ao fato de que os seres humanos inevitavelmente dividem a superfície da terra com desconhecidos, que assim podem permanecer, ou tornar-se amigos, e de quem eles podem desgostar. Se a obra reme- 
te ao mundo em seu aspecto objetivo, a ação remete a seu aspecto intersubjetivo.

Tais distinções, apenas esboçadas acima, requerem alguns esclarecimentos. O primeiro é que Arendt fala em condição humana, e não em natureza humana. Esse deslocamento lhe possibilita tomar o indivíduo no mundo, entendendo-se por mundo um conjunto de artefatos materiais, institucionais, simbólicos, e uma grande teia de histórias entrelaçadas que abriga as interações individuais, nas quais uns e outros se afetam mutuamente e pelas quais suas histórias, tanto atravessam as de outros, quanto são atravessadas pelas deles. Se natureza humana remete a uma espécie de substrato comum descolado do espaço e retirado do tempo, condição humana aponta para indivíduos situados, igualmente subjugados pelas necessidades do corpo, mas também singulares. No limite, Arendt vai encontrando assim um lugar para o que nos une, o que nos separa e, como veremos, o que nos põe em relação. Um segundo esclarecimento é que a vida humana tem, para Arendt, tanto uma dimensão biológica, relacionada, como dissemos acima, ao corpo e à espécie, quanto uma dimensão biográfica, que se estende do nascimento à morte, e é urdida nas interações e cuja autoridade repousa, estranhamente, nos outros. O ator arendtiano não é propriamente autor de sua história: ele precisa contá-la para dar sentido à própria vida, mas só aqueles que o assistem ou o ouvem sabem quem ele é. E é em relação a eles, aos seus contemporâneos, antecessores e sucessores, que sua história pode ter sentido. Arendt usa os termos gregos zoé e bíos para dar conta dessas dimensões distintas da vida, a biológica e a biográfica.

Por razões distintas, a modernidade encerra potenciais ameaças a ambas. Por isso, um propósito de A condição humana é pensá-la criticamente. Arendt identifica algumas de suas características, entre as quais a intromissão de processos naturais no espaço público, com o que ela chama de ascensão do animal laborans, que se dedica ao trabalho para sustentar o corpo e o consumo, com a consequente des- truição do mundo natural e daquele fabricado por mãos humanas. Dessas características da modernidade resultariam um avanço da economia, isto é, das atividades originariamente ligadas à casa sobre o espaço público, a ponto de transformar a política, de uma experiência de liberdade, em administração da vida, com seu consequente rebaixamento, para Arendt. É nesse processo de expansão da economia em relação ao público que se constitui, enfim, o social, um espaço híbrido, no qual interesses privados adquirem importância pública e assumem crescente protagonismo em relação à vida privada e à política.

Quatro anos após a publicação de $A$ condição humana, um livro de peso foi dedicado à análise da esfera pública. Em Mudança estrutural da esfera pública, de 1962, Habermas delineia o conceito a partir de uma reconstrução histórica e social que remete ao ponto em que Arendt teria parado em 1958, a saber, o final do século XVIII, das revoluções francesa e americana. Em seu livro, Habermas argumenta que, naquele momento, a esfera pública torna-se um elemento funcional da ordem burguesa, pois lhe foi conferido um status normativo, por meio do direito e das instituições, que articulavam a sociedade civil com uma autoridade estatal correspondente às suas necessidades. De outra parte, os princípios republicanos e liberais fomentaram o surgimento de uma esfera pública informal, nos cafés, salões e associações literárias, proporcionando um espírito crítico que se consolidava como uma antítese cultural à aristocracia. Nesse processo, mediado e publicizado pela imprensa, permitiu-se disseminar uma crescente politização da vida, ampliando-se o exercício da crítica também à autoridade política e ao poder do Estado (Habermas, 2013; Lubenow, 2007). Benhabib (2003) pondera que esse fenômeno foi percebido por Arendt, inclusive com destaque para a presença feminina na Berlim de meados do século XIX em seu Rahel Varnhagen: a vida de uma judia alemã na época do Romantismo, mas não mereceu uma análise parcimoniosa em A condição humana. 
Nos dois séculos seguintes, em diagnóstico compartilhado por Arendt e Habermas, o advento do Estado de Bem-Estar Social diluiu as fronteiras entre o público e o privado. $\mathrm{O}$ crescente intervencionismo estatal e a ampliação de suas funções de implementação de direitos, num contexto de sociedade e de meios de comunicação de massa, ressignificaram a função da esfera pública, que se tornou mais um espaço burocrático-administrativo de regulação social e, portanto, de reprodução da ordem e objeto de manipulações ao invés de um espaço de crítica, emancipação e transformação. Em $A$ condição humana, esse processo é identificado como a ascensão do social, descrito por Arendt como a crescente dedicação do tempo a atividades relacionadas com os processos vitais e a vida social, uma vida de associação por semelhanças que contribui para a normalização de comportamentos. No pensamento de Arendt, a crítica do social lança luz sobre a busca pela distinção - um processo potencialmente agonístico - e a espontaneidade, que tornam a ação imprevisível e, portanto, não controlável, o que é importante, se pensarmos que elementos totalitários podem estar presentes em sociedades democráticas (Arendt, 1973) e é preciso cogitar formas de resistência.

Seja como for, dois efeitos da ascensão do social são, para Arendt, a diluição da separação entre público e privado e o comprometimento das condições da ação, entre as quais จิ a possibilidade de retirada do espaço público o. para o diálogo de si consigo mesmo e o trabalho ¿े de conciliação com o mundo (Arendt, 1994b). ¿े Em Habermas (1989, 2013), essas mudanças ô evidenciam a complexificação da esfera públi¿. ca contemporânea e a necessidade de manter o ळ que ele chama de ação comunicativa blindada

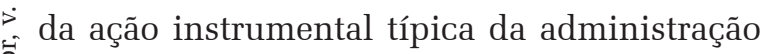
pública e do mercado.

Segundo o diagnóstico habermasiano, apenas o fortalecimento da esfera pública e de uma razão discursiva poderia deter o avanço da racionalidade sistêmica, que tende a extrapolar seu campo de ação, contaminando as relações sociais, culturais e políticas, e colonizando o mundo da vida, uma espécie de pano de fundo cultural comum a uma dada sociedade. Nesse sentido, a esfera pública assume um papel central, não se resumindo às instituições políticas estatais, mas a um conjunto de associações e organizações que povoam as relações humanas. Funcionando como uma "rede adequada para a comunicação de conteúdos, tomadas de posição e opiniões na qual os fluxos comunicacionais são filtrados e sintetizados a ponto de se condensarem em opinióes públicas enfeixadas em temas específicos" (Habermas, 1997, v. II, p. 92), a "esfera pública constitui principalmente uma estrutura comunicacional do agir orientado pelo entendimento" (Habermas, 1997, v. II, p. 92). Se, em sua origem moderna, a esfera pública era apenas a reunião das esferas privadas que compunham um público, na construção habermasiana, com o passar do tempo e a complexificação social, suas estruturas comunicacionais conhecem uma generalização cada vez maior. Nesse processo, há um desacoplamento entre os conteúdos e tomadas de posição e os contextos densos das interações simples de pessoas ou grupos, bem como a necessidade de maior explicação e tradução desses conteúdos ao público geral. Quanto mais as esferas públicas se desligam de suas presenças físicas, integrando o espaço virtual, mais abstrata se torna essa passagem (Habermas, 1997, v. II, p. 93). ${ }^{1}$

Uma crítica pertinente à forma como Arendt pensa o espaço público é a de que ela não olha para sua complexificação com a ascensão do social, mas insiste em uma separação rígida entre os espaços da vida ativa e sua associação a atividades específicas (Benhabib, 2003). Privilegiando as interações face-a-face ou mediadas por instituições, Arendt se furta

${ }^{1}$ Vale ressaltar, porém, que, ao fazer essa reflexão, nos anos 1990, Habermas tinha em mente um conjunto passivo de leitores, espectadores e ouvintes que recebiam conteúdos midiáticos, sendo a comunicação, pois, mediada pelos canais de comunicação de massa. Em tempos de internet e redes sociais, esse conjunto pode ser tanto mais ativo quanto mais passivo e atuar com forte influência nessa esfera pública, tornando esse ambiente ainda mais complexo. 
a pensar o papel da mídia na política, o que é interessante porque, contrariando a tradição da filosofia, ela pensou as opiniões em sua positividade, caracterizou-as como sendo próprias ao domínio da política e contribuiu ela mesma com veículos de imprensa, como a revista New Yorker. Inspirado no modelo da democracia grega, o espaço público arendtiano constitui-se com a igualdade perante a lei, tendo por característica interações mediadas por objetos fabricados por mãos humanas e pelas instituições. Nesse sentido, Arendt estaria mais próxima de uma visão republicana da política, oposta a uma visão liberal e distinta da via procedimental aberta pela teoria do discurso habermasiana. ${ }^{2}$

A via comunicativa e intersubjetiva é defendida tanto por Arendt como por Habermas, que guardam similaridades e diferenças importantes. Enquanto para Habermas a ênfase da ação está no seu processo discursivo, na formação de consensos pela ação racional comunicativa, e incorpora a dimensão estratégica (Habermas, 1980), para Arendt, influenciada pelos antigos, o cerne da política está na própria ação em concerto, marcada pelo fato inexorável da pluralidade. Esta condição humana na terra torna a ação potencialmente tão consensual quanto agonística, tão necessária quanto contingente (Canovan, 1983).

Na concepção de espaço público, Arendt é tributária dos gregos antigos, e seu retorno a

${ }^{2}$ Ao mesmo tempo, ao afastar o elemento estratégico do universo político, já que, como veremos, para Arendt a mentalidade ou racionalidade instrumental é típica do homo faber, o espaço público arendtiano é considerado por alguns autores como um fim em si mesmo (Habermas, 1980) e, portanto, de pouca aplicação prática (Elster, 1999). Essa afirmação procede na medida em que, na construção arendtiana, a ação política diz respeito ao papel do indivíduo de instituir um espaço para que os seres humanos possam opinar, buscar distinguir-se uns dos outros e agir de maneira a dar curso ao imprevisível, o que ela chama de fazer milagres (Arendt, 1998). Ao contrário do trabalho, marcado por uma circularidade estéril, e da obra, marcada pela produção de objetos concretos, externos e duráveis, a política seria o espaço da possibilidade de transformação pela prática, discursiva e performática, o que significa que a ação política teria um sentido, e não um resultado. Na modernidade, com a ascensão do social, um dos principais problemas seria, assim, a reconfiguração desfigurada do espaço público, cuja função passou a ser a regulação das necessidades do trabalhador, perdendo sua condição de reino da liberdade. eles pode ser interpretado como uma forma de nostalgia. Mas também podemos entender que Arendt não almeja com esse recuo uma reprodução da democracia ateniense, e sim pensar criticamente o espaço público moderno, a relação da política com o social e o privado, tendo em vista a possibilidade da política em sua plena dignidade, ou seja, aberta à espontaneidade e à distinção, podendo esta ser entendida como uma forma de apreciação da singularidade. O retorno de Arendt aos antigos se dá por seu interesse presente, informado pela experiência do totalitarismo, para encontrar parâmetros a uma crítica da modernidade, da possibilidade da política em resposta a uma vida administrada, do deslocamento da ação pelo comportamento, da espontaneidade pela normalidade.

Retornando à experiência singular da democracia ateniense, Arendt (1998) entende que o público se constitui originariamente pela reunião de indivíduos em torno de assuntos ou problemas específicos, os quais assim se tornam assuntos comuns. Mas, se o público se constitui pela reunião, o que Arendt ilustra remontando a Homero, a pólis lhe teria conferido estabilidade através da lei, que o demarca tal como o muro que circunscrevia fisicamente o espaço da política. Este é o espaço da isonomia, da isegoria e da isocracia, ou seja, da paridade no falar, ser ouvido e decidir. Trata-se de um espaço em que se age pela palavra, a troca de opiniões voltada para a persuasão, estando excluída a violência, que no mundo antigo justificou tanto a subjugação pela escravidão quanto os processos de fabricação, destrutivos do mundo natural.

A igualdade que constitui o espaço da política é aquela igualdade que hoje denominaríamos formal. Na Grécia antiga ela, de fato, está ancorada em uma série de exclusões, notadamente das mulheres, dos estrangeiros e dos escravos. Nessa configuração, a escravidão era uma instituição fundamental porque a cidadania dependia de encontrar uma solução para o constrangimento que as necessidades vitais representariam à imparcialidade no trato 
dos assuntos comuns (Arendt, 2018b), ou seja, a que os cidadãos não decidissem os assuntos da cidade sob seu jugo. Para dar conta conceitualmente dessa condição de ingresso no antigo espaço da política, Arendt (1990, 2016, 2018a) distingue liberação de liberdade, uma distinção que ela aprofundará em Sobre a revolução, de 1963. A liberdade é o sentido da ação (Arendt, 2005) e a ação é não violenta por definição, ao passo que a liberação, a disposição de recursos materiais para a satisfação das necessidades vitais como uma condição para estar, entre pares, é pré-política e pode compreender a violência (Arendt, 1990; 1998).

Nessa construção, a política é aquilo que se passa entre indivíduos quando eles agem em conjunto. Na ação os indivíduos se tornam atores, comunicam-se uns com os outros e comunicam aos outros quem são. Pensando com Santo Agostinho, Arendt parte do pressuposto de que todos os indivíduos são novos começos por si sós, pois ingressam pelo nascimento em um mundo que os precede e que será transformado por eles; por isso, também lhes é facultado introduzir pela ação algo novo no mundo. Concebida nesses termos, a política é necessariamente intersubjetiva, isto é, passa-se entre indivíduos, não podendo se dar em isolamento e sendo dependente da manutenção do espaço-entre, que separa e relaciona, e é, na prática, assegurado por artefatos e instituições.

Como se pode notar a esta altura, Arendt ธิ não pensa a política com centro no Estado, nem ণ o poder como dominação, e sua possibilidade, ¿े para ela, assenta-se em uma série de condições. ¿े A primeira, como antecipamos, é a igualdade $\because$ perante a lei, que possibilita aos atores se dis- tinguirem uns dos outros sem temerem que sua ळ distinção resulte em desigualdade. A igualda$>$ de consistiria, assim, em uma forma de lidar com as diferenças. Outra condição, também já mencionada, é a liberação em relação às necessidades vitais. Esse é um ponto muito controvertido de seu pensamento, que inclusive leva estudiosos de Arendt, como Richard Bernstein (1986), a contestar a utilidade de sua distinção dos espaços da vida ativa. No limite, ela esvaziaria a política do debate acerca de questões de justiça material, o que faz repensar como Arendt pensa o problema da assimetria de poder. Por fim, a política para Arendt só é possível porque somos, ao mesmo tempo, diferentes uns dos outros e semelhantes uns aos outros, o que significa que precisamos e conseguimos nos comunicar, ainda que não necessariamente, ou mesmo dificilmente, concordemos uns com os outros. Há possibilidade de entendimento mútuo, entendimento das opinióes uns dos outros, sem consenso.

Mas por que precisamos falar uns com os outros? Para Arendt, uma resposta a essa pergunta passa, entre outras coisas, pelo fato de que cada um tem uma perspectiva singular e insubstituível do mundo: recuperando o sentido do verbo grego antigo dokein, Arendt dirá que o mundo se abre diferentemente para cada um de nós (Arendt, 1994c). Essa abertura informa as nossas opiniões, que são aquilo que nos parece, ao passo que é parte fundamental na construção de tudo aquilo que é factual, dos fatos como algo compartilhado, ou, se preferirmos, da verdade factual (Arendt, 1972; 2016), pelo que Arendt entende aquilo que é visto por muitos de ângulos diferentes e por isso só pode ser frágil. ${ }^{3}$ Para ela, a despeito dessa fragilidade, a possibilidade de opinar depende dessa verdade e o estatuto das opiniões na política requer certa distância da verdade lógica e filosófica, a verdade absoluta, eterna, e, por conseguinte, tirânica (Arendt, 1994c). Com isso, Arendt, por um lado, afasta a prática da negação dos fatos, da organização da mentira e da falsificação da realidade e, por outro, aponta para o problema dos especialistas na democracia, ou na República.

Para resumir o que dissemos até aqui, na topologia da vida ativa, o espaço público é

${ }^{3}$ Uma crítica posterior e pertinente do feminismo acadêmico (Benhabib, 1993; Young, 1990) a Arendt nesse ponto é que ela não contempla, em sua reflexão, identidades com as quais estamos habituados a pensar a política nos nossos dias, como raça, gênero, orientação sexual, e que já eram mobilizadas na aç̃o social em demandas por justiça. Em parte a dificuldade ou recusa de Arendt a pensá-las pode estar associada a seu entendimento do lugar do público e do privado no mundo moderno. 
aquele estabelecido entre indivíduos iguais perante a lei que se ocupam das coisas do mundo falando dele, trocando ideias e buscando persuadir uns aos outros. É um domínio em que o absoluto não cabe e que abriga o relativo, as opiniões (Arendt, 1994c): ele pode abrigá-las em sua positividade porque tem, na verdade factual, um elemento pré-político. Esse espaço é, ademais, constituído pela e para a ação tanto quanto por e para atores. Como dissemos parágrafos atrás, trata-se de um espaço de aparecimento, em que por atos e falas os atores revelam quem são, para além dos atributos que compartilham com outros, e podem buscar a distinção, mostrar sua singularidade, inscrever seu nome e sua biografia na grande e frágil teia dos assuntos humanos que é a história. Para isso, a pluralidade é uma condição não só porque a ação é conjunta por definição e é nela que o ator se revela, mas também porque o testemunho e o reconhecimento dos outros é a garantia da memória do ator e de que seus feitos serão contados.

Esse espaço, inequivocamente intersubjetivo, tem uma dimensão que podemos considerar equivocamente objetiva. Ela é equívoca, primeiro, porque ora compõe o espaço público, ora é uma condição para que ele se estabeleça, e depois porque, como Arendt (1978) dirá muito mais tarde, todo subjetivo é objetivo a outro alguém. Com frequência, a dimensão objetiva do espaço público aparece como uma condição da ação, encontrando nos muros da cidade e na lei sua representação. Tomada como tal, a importância dessa dimensão relaciona-se com o fato de a ação ser, para Arendt, incontrolável e imprevisível por princípio, o que marca uma distância entre sua concepção de política e a da tradição, concebida ou em termos de comando e obediência, ou como sendo instrumental, calculável e, por conseguinte, previsível e controlável. Para Arendt (1998), ao contrário, toda ação compreende um começo, que, como dissemos, pode resultar na introdução de algo novo no mundo; mas não se pode controlar seu curso, nem, portanto, prever seu desfecho. Mesmo os espectadores, que podem contemplá-la e teriam o que Immanuel Kant chamou de um olhar desinteressado sobre ela, só têm uma ideia clara a seu respeito ao final dos acontecimentos.

Por esses dois aspectos, a incontrolabilidade e imprevisibilidade, a ação encerra, ela mesma, dois remédios, segundo Arendt: o perdão e a promessa. O perdão, uma faculdade individual, abre caminho para novos começos; a promessa pretende vincular os atores a princípios da ação e se consubstancia em instituições. Em A condição humana essas instituições, que são um aspecto objetivo do público, importam por conferirem estabilidade à política. Elas são, nesse sentido, uma condição de possibilidade do novo sem ruptura, sem a deflagração incessante de revoluções. Outro modo de olhar para o que estamos chamando de dimensão objetiva do público é como suporte físico da ação, sem o qual público não chegaria a se formar. Judith Butler (2015) explora esse caminho enfocando como o público se forma por assembleias, ou seja, pela reunião espontânea de multidões que transformam espaços físicos e objetos. Essa reunião, no entender de Butler (2015), institui o público pela formação intersubjetiva e transformadora do material; mas a ação também é mais dependente das condições materiais do que Arendt supõe: não por acaso, as assembleias com frequência contestam e demandam acesso a condições para agir.

A topologia arendtiana dos espaços da vida ativa tem sido um problema teórico tanto no debate sobre questões econômicas e sociais quanto no debate feminista. Como dissemos, Benhabib (2003) argumenta que há, em A condição humana, uma tensão entre uma abordagem inspirada na fenomenologia, que pressupõe uma atividade essencial a cada espaço, e uma abertura para uma abordagem centrada na narração, que remete à influência de Walter Benjamin sobre Arendt. Essa abertura possibilitaria tomar os espaços da vida ativa como sendo mais plásticos e porosos do que eles parecem ser, na forma rígida que assumem nas 
distinções arendtianas e sujeitos a reconfigurações na ação por atores aos quais, na prática, nada é dado, nem interdito quando se trata de assuntos comuns. Podemos entender, nessa linha de argumentação, que as distinções arendtianas adquirem um aspecto rígido por serem forjadas para elucidar por contraste, mas não é descabido entender que os espaços da vida ativa se moldam e se reconfiguram em função das atividades a que os indivíduos se dedicam. Por isso, tem sentido olhar para o que estamos fazendo na pandemia e repensar o espaço público especialmente, considerando essas práticas.

\section{UMA RECONFIGURAÇÃO DO ES- PAÇO PÚBLICO NA PANDEMIA DE COVID-19?}

No início de janeiro de 2020, soube-se que a China tentava conter uma epidemia causada por um novo tipo de coronavírus, nomeado de SARS-Cov-2. A Organização Mundial da Saúde (OMS) já tinha sido informada que uma pneumonia de etiologia desconhecida acometia pessoas em uma região específica do país. ${ }^{4}$ As manifestações mais severas da doença causada pelo novo vírus, a Covid-19, caracterizavam-se por infecções respiratórias agudas e morbidade elevada em comparação com a gripe comum. A doença era menos letal que precedentes suas, como a SARS, mas já se sabia que o tempo de ชิ internação por ela era prolongado, o que sobreo. carregava os serviços de saúde e acabava resul¿ tando em elevado número de mortos.

Também se sabia que o vírus era muito contagioso e transmitido pelo ar. Para conter ¿ sua transmissão, a China adotou medidas se-

iิ 4 World Health Organization. Novel Coronavirus Report (2019-NCoV). Situation Report 1. 21 January 2020.

Disponível em < https://www.who.int/docs/default-source/ . coronaviruse/situation-reports/20200121-sitrep-1-2019-ncov.pdf?sfvrsn=20a99c10 4> (acessado em 14 de julho IJ 2020); Watanabe, Phillipe e outros. Tudo o que você precisa saber sobre o novo coronavírus Sars-CoV-2. Folha de S. Paulo, 22 de janeiro de 2020. Disponível em < $\underline{\text { ht- }}$ tps://www1.folha.uol.com.br/equilibrioesaude/2020/01/ veja-o-que-se-sabe-ate-agora-sobre-o-coronavirus-chines. shtml > (acessado em 14 de julho de 2020). veras. ${ }^{5}$ Interditou a circulação e a reunião de pessoas, o que implicou um esvaziamento dos espaços físicos das cidades, interrompeu a produção, reorganizou serviços essenciais, além dos serviços de saúde, e suspendeu o comércio com outros países, pois o vírus viajaria com as pessoas $^{6}$ e a epidemia adquiriria dimensão global, ou seja, resultaria em uma pandemia, o que acabou ocorrendo. ${ }^{7} \mathrm{O}$ epicentro da epidemia era a cidade de Wuhan, na província de Hubei. Imagens de suas ruas desertas, dos corredores vazios de seu aeroporto correram o mundo.

Uma política semelhante à chinesa foi adotada em países vizinhos, nomeadamente a Coreia do $\mathrm{Sul}^{8}$ e o Japão, com eficácia em ambos. Apesar disso, as imagens que circularam não parecem ter acionado qualquer alarme. Essa sua recepção pode estar associada ao fato de que outras pandemias, inclusive detectadas na China, como a da SARS, já tinham sido controladas nas últimas décadas. Também podem ter contribuído para ela a percepção de que há uma distância entre "nós" e "eles", ou seja, de que nós, ocidentais, estávamos seguramente separados e de que a severidade das medidas era própria de sociedades percebidas como ex-

5 BBC. China coronavirus: Lockdown measures rise across Hubei province. BBC, 23 January 2020. Disponível em <https:/www.bbc.com/news/world-asia-china-51217455 > (acessado em 14 de julho de 2020); AFP. China isola área com 40 milhões para conter coronavírus; 41 já morreram. Folha de S. Paulo, 24 de janeiro de 2020. Disponível em <https://www1.folha.uol.com.br/equilibrioesaude/2020/01/china-isola-area-com-40-milhoes-para-conter-coronavirus-26-ja-morreram.shtml $>$ (acessado em 15 de julho de 2020).

${ }^{6}$ OMS eleva a ameaça internacional do coronavírus para muito alta. Folha de S. Paulo, 28 de fevereiro de 2020. Disponível em <https://www1.folha.uol.com.br/equilibrioesaude/2020/02/oms-eleva-a-ameaca-internacional-do-coronavirus-para-muito-alta.shtml $>$ (acessado em 15 de julho de 2020).

7 WHO. WHO Director-General's opening remarks at the media briefing on COVID-19 - 11 March 2020. Disponível em <https://www.who.int/dg/speeches/detail/who-director-general-s-opening-remarks-at-the-media-briefing-on-covid-19---11-march-2020> (acessado em 15 de julho de 2020); Watanabe, Phillippe. OMS declara pandemia de novo coronavírus Sars-CoV-2. Folha de S. Paulo, 11 de março de 2020. <https://www1.folha.uol.com.br/equilibrioesaude/2020/03/oms-declara-pandemia-do-novo-coro-

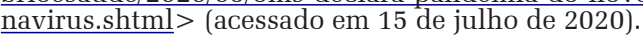

${ }^{8}$ BBC. Coronavirus: South Korea 'emergency' measures as infections increase. BBC, 21 February 2020. Disponível em <https://www.bbc.com/news/world-asia-51582186 > (acessado em 14 de julho de 2020). 
tremas. A postura traduziu-se em uma demora fatal $^{9}$ na adoção de medidas para conter o contágio em massa da população.

Outros elementos para a compreensão dessa demorada resposta seriam o caráter sem precedente da paralisação da economia que a questão sanitária impunha e a relação entre as penosas medidas para o enfrentamento da pandemia, a invisibilidade do vírus e a evolução exponencial do contágio. Estes últimos elementos podem ter cumprido um papel importante porque, como Arendt (1973) argumenta, as pessoas tendem a insistir na continuidade da vida habitual, na 'normalidade', diante de situações disruptivas. Não custa imaginar que a visibilidade apenas microscópica do vírus e o desafio que o entendimento de dados científicos, como a dispersão exponencial da doença, representava podem ter tornado o sacrifício da continuidade da vida em nome de algo por vir difícil de compreender e aceitar.

Quando enfim foi adotado, a partir de março de 2020, o isolamento social forçado na Itália, ${ }^{10}$ Espanha $^{11}$ e França ${ }^{12}$ rendeu uma série de medidas de ordem prática, destinadas, entre

9 Sandford, Alasdair. Coronavirus: Italy's prosecutors question PM Giuseppe Conte over lockdown 'delay'. Euronews, 12 June 2020. Disponível em <https://www.euronews.com/2020/06/12/coronavirus-italy-prosecutors-question-pm-giuseppe-conte-over-lockdown-delay $>$ (acessado em 14 de julho de 2020).

${ }^{10}$ AFP. Itália decreta quarentena na Lombardia, Veneza e outras regiões por coronavírus. Folha de S. Paulo, 7 de março de 2020. < https://www1.folha.uol.com.br/equilibrioesaude/2020/03/italia-quer-quarentena-na-lombardia-veneza-e-outras-regioes-por-coronavirus.shtml> (acessado em 15 de julho de 2020); Di Donato, Valentina e outros. All of Italy is in lockdown as coronavirus cases rise. CNN, 13 March 2020. Disponível em < https://edition.cnn. com/2020/03/09/europe/coronavirus-italy-lockdown-intl/ index.html > (acessado em 14 de julho de 2020).

${ }^{11}$ Sousa Pinto, Ana Stela. Espanha fecha 47 milhões em casa a partir de segunda. Folha de S. Paulo, 147 de março de 2020. Disponível em <https://www1.folha.uol.com.br/ equilibrioesaude/2020/03/espanha-determina-que-populacao-fique-em-casa-a-partir-de-segunda.shtml> (acessado em 15 de julho de 2020); Jones, Sam. Spain orders nationwide lockdown to battle coronavirus. The Guardian, 14 March 2020. Disponível em <https://www.theguardian.com/world/2020/mar/14/spain-government-set-to-order-nationwide-coronavirus-lockdown $>$ (acessado em 14 de julho de 2020)

${ }^{12}$ Erlanger, Steven. Macron declares France 'at war' with virus, as E.U. proposes 30-day travel ban. New York Times, 16 March 2020. Disponível em <https://www.nytimes.com/2020/03/16/world/europe/coronavirus-france-macron-travel-ban.html > (acessado em 14 de julho de 22020). outras coisas, a assegurar condições materiais mínimas para que todos pudessem se manter isolados. Rendeu, ademais, uma vasta produção de imagens registradas em fotos ${ }^{13} \mathrm{e}$ vídeos, às quais não muito tempo depois se somariam aquelas procedentes de grandes cidades inglesas e americanas.

Um conjunto dessas imagens mostra efeitos da paralisação da vida citadina e a redução das atividades econômicas sobre o meio ambiente. A melhoria da qualidade do ar na China $^{14}$ já havia sido registrada e, quando a Europa foi atingida, rapidamente circularam registros dos canais de Veneza limpos. ${ }^{15} \mathrm{Ou}$ tro conjunto de fotografias capturava grandes vias, pontos turísticos, prédios históricos comumente disputados centímetro a centímetro esvaziados. A Champs Elysées, a Torre Eiffel e as margens do Sena em Paris, a Praça São Marco em plena quaresma ${ }^{16}$ e o Duomo na Itália, a Trafalgar Square na Inglaterra, a Times Square nos Estados Unidos, símbolos da modernidade ocidental e de certa vida cosmopolita, aparecem desertos em imagens veiculadas em jornais impressos, televisivos e em sites. Esse material também circulou em mídias sociais, sendo acessado por pessoas em diferentes contextos locais, em geral por dispositivos de uso pessoal, como celulares. Sua circulação conferiu alcance global ao esvaziamento daqueles espaços e contribuiu para sua produção como

${ }^{13}$ Mundo em isolamento devido ao coronavírus. Folha de S. Paulo, 20 de março de 2020. Disponível em < https:// fotografia.folha.uol.com.br/galerias/1661700790427625 -mundo-em-isolamento-devido-ao-coronavirus \#foto-1661700790572868> (acessado em 15 de julho de 2020).

${ }^{14} \mathrm{He}$, Guojun e outros. The short-term impacts of COVID-19 lockdown on urban air pollution in China. Nature Sustainability, 7 July 2020. Disponível em < https://www. nature.com/articles/s41893-020-0581-v > (acessado em 14 de julho de 2020).

${ }^{15}$ Di Donato, Valentina e outro. Venice's canal water looks clearer as coronavirus keeps visitors away. Disponível em $<$ https://edition.cnn.com/travel/article/venice-canals-clear-water-scli-intl/index.html $>$ (acessado em 14 de julho de 2020).

${ }^{16}$ AFP e Reuters. Contra coronavírus, Francisco reza m frente a crucifixo da peste negra. Folha de S. Paulo, 27 de março de 2020. Disponível em < https://www1.folha.uol. com.br/mundo/2020/03/contra-coronavirus-francisco-reza-em-frente-a-crucifixo-da-peste-negra.shtml > (acessado em 15 de julho de 2020). 
uma experiência compartilhada de perda do mundo, ainda que individualmente sentida.

Essa dimensão globalmente compartilhada da doença, do esvaziamento dos espaços e da retirada para a casa foi reforçada por um terceiro conjunto de imagens, que registrava formas de interação que as pessoas encontraram para romper o isolamento. As mais memoráveis delas mostravam vizinhos ouvindo música ou cantando juntos desde as varandas e janelas em diferentes cidades europeias. $\mathrm{O}$ registro dessas cenas fazia pensar na criação de públicos contingentes pela interação com primado da audição, ou seja, pela estética da palavra (o som e a letra), e isso a partir de áreas de convivência em espaços a rigor privados. Esses públicos pareciam instituídos acionando afetos ligados a artefatos de cultura por um desejo de estar junto: era como se se buscasse reconstituir por tais práticas o mundo que se sentia perdido.

Se, por um lado, a música apareceu como um "lugar de encontro", por outro, na impossibilidade da reunião física, a dimensão visual ganhou proeminência com práticas como a disposição de outdoors e, no Brasil, as projeções em arranha-céus das cidades. Essas projeções foram usadas durante 'panelaços' ${ }^{17}$ - a prática de bater panelas enquanto o presidente se pronuncia à nação - para manifestar apoio ao SUS, o Sistema Único de Saúde, às medidas adotadas pelos governadores e para protestar contra స్ิ o presidente pela condução da resposta à pano. demia. ${ }^{18}$ Liam-se frases como "Respeite o povo, ¿े sua máscara caiu”, "Pq não se cala?”, “Todo dia um novo dia da mentira - no país da fake news ì de Bolsonaro", que se programava um compu¿. tador para projetar em prédios nos arredores, ou ले seja, de casa para os espaços das cidades.

${ }^{17}$ FERRAZ, Adriana. Projeções em prédios viram nova forma de se manifestar durante panelaços. Estadão, 29 de março de 2020. Disponível em < https://politica.estadao.com. br/noticias/geral,projecoes-viram-nova-forma-de-se-manifestar,70003252143 > (acessado em 15 de julho de 2020).

${ }^{18}$ Folha de S. Paulo. Projeções contra Bolsonaro durante a pandemia. Disponível em < https://fotografia.folha.uol.com. br/galerias/1663251229350200-projecoes-contra-bolsonaro-durante-a-pandemia > (acessado em 15 de julho de 2020).
Tais projeções em grande escala chamaram a atenção e foram parar nas páginas dos jornais. Como eram registradas em fotos e vídeos, as imagens, as frases, notícias da própria prática de projetá-las e como fazê-lo também circularam em mídias sociais. Em grupos de WhatsApp que integramos, as pessoas de fato demonstraram interesse nessa forma de ação, que lhes permitia compensar o isolamento e certa sensação de impotência diante da inação do governo federal e da impossibilidade de reunião. As projeções eram uma apropriação do espaço físico em sua materialidade para a inscrição de falas do presidente, para a manifestação de opiniões, e apareciam como uma irrupção inesperada em cenários da vida urbana, a atrair olhares e pessoas à janela. Mas eram, também, ações sem atores visíveis.

Outro efeito da política de isolamento social foi a concentração de interações em plataformas para encontros e reuniões, como Google Meet e Zoom, e em mídias como o Twitter e o Instagram. Ela também resultou em uma ampliação do uso de plataformas de vídeos, como o YouTube, para transmissões em tempo real, a prática das "lives" por artistas, cientistas, especialistas em diferentes áreas, ativistas, transmitidas desde casa. Este espaço, a casa, próprio da vida privada, abrigou materialmente a vida pública em ambientes digitais. A partir de seu espaço físico e de sua conexão de internet, tornaram-se frequentes as conversas sobre a pandemia e assuntos do mundo, a morte e angústias pessoais durante a quarentena; performances de indignação, no caso do Brasil, contra a condução da pandemia pelo governo federal e falas do presidente da República; a crítica em massa de determinadas postagens ou tuítes; as transmissões para compartilhar conhecimento sobre a pandemia e de distintas áreas do conhecimento, para buscar entendimento da questão sanitária, econômica, social ou política, para entretenimento, para a articulação de ações de solidariedade e de engajamento, como aquela que observamos no Brasil em torno do auxílio emergencial. Esses usos das mídias sociais e do YouTube não são um fenômeno novo, mas ganharam 
dimensão inédita com a pandemia, suscitando uma série de questões.

Tais mídias possibilitam encontros e trocas que têm o condão de reabilitar a conversa, o que importa em geral e especialmente em contextos nos quais o debate público parece 'polarizado', isto é, organizado em torno de duas posições cristalizadas e radicalmente antagônicas. Pensando com Arendt (1992), conversas representam uma reabertura da possibilidade de repensar crenças, preconceitos, dogmas e as próprias ideias, ou seja, de alargar mentalidades e construir espaços pela e para a experimentação de novas formas de ação, que podem transbordar de ambientes digitais para o espaço físico, para a interação face-a-face.

Um aspecto a considerar, no entanto, é que a forma de funcionamento das mídias e plataformas de um modo geral não é amistosa ao silêncio e, como o tempo delas é outro, acabam impelindo a responder e a buscar respostas imediatas. De uma parte, esse modo de funcionamento favorece os engajamentos e a circulação das falas, até porque cria um ambiente propício a confrontos, que fazem falar e ser visto. Por isso se pode afirmar que ele facilita a formação de público para certos discursos. É interessante pensar, de outra parte, que essas interações tendem a se dar em um tempo diferente das interações face-a-face, que, como vimos, inspiraram a elaboração tanto de Arendt quanto de Habermas acerca do espaço público ou da esfera pública. Para ambos, o tempo dessas interações seria o tempo das opiniões informadas pelas trocas, pelo conhecimento compartilhado quando for o caso e forjadas tanto em pensamento quanto na pluralidade desse espaço, ou o tempo do agir conjunto que irrompe no espaço. Cabe pensar, portanto, se o deslocamento das interações para as mídias sociais não cria condições propícias a uma espécie de descolamento entre fala e opinião, tal como Arendt a entende - isto é, relacionada com uma perspectiva individual sobre o comum, o pensamento e o juízo -, bem como a usos da palavra com vistas primordialmente à produção de efeitos pretendidos sobre a audiência.
Pensamos que o descolamento entre fala e opinião, tomada no sentido que Arendt lhe empresta, pode ajudar a entender por que a circulação de mais manifestações não significa, necessariamente, maior pluralidade nem de ideias, nem de perspectivas. Pode ajudar a compreender, ademais, um problema que adquiriu contornos dramáticos com a pandemia: o negacionismo dos fatos e do conhecimento.

$\mathrm{O}$ vírus afinal encontrou no Brasil uma sociedade desigual e empobrecida - aspectos de que não nos ocuparemos aqui, mas que sua evolução cuidou rapidamente de evidenciar - e terreno fértil à propagação de mentiras e desinformação. ${ }^{19}$ No que se refere à propagação de mentiras e desinformação, ela se insinua na forma que o debate público sobre a pandemia assumiu já ao início, com o presidente e empresários buscando organizá-lo em torno de pares como distanciamento/isolamento - emprego e proteção da vida - manutenção da vida, ${ }^{20}$ contrariando inclusive o entendimento de economistas a respeito. Esses pares distorceram o debate por criarem uma falsa dicotomia, ancorada na equivalência de valores que economistas, por exemplo, afirmavam não serem concorrentes.

$\mathrm{O}$ intuito primordial do presidente e seus apoiadores parecia ser apelar "[a]o sexto e mais elevado sentido" (Arendt, 1998, p. 274), o senso comum, que ajusta o homem (sic) à realidade a ele circundante, para validar sua

${ }^{19}$ SROUGI, Miguel. Coronavírus no Brasil: a pandemia e os pandemônios. Folha de S. Paulo, 20 de março de 2020. Disponível em <https://www1.folha.uol.com.br/opiniao/2020/03/coronavirus-no-brasil-a-pandemia-e-os-pandemonios.shtml> acessado em 14 de julho de 2020).

${ }^{20}$ Brasil. "Venceremos o vírus", afirma Bolsonaro em pronunciamento aos brasileiros. Disponível em < https:// www.gov.br/planalto/pt-br/acompanhe-o-planalto/noticias/2020/03/venceremos-o-virus-afirma-bolsonaro-em-pronunciamento-aos-brasileiros $>$ (acessado em 15 de julho de 2020); Coletta, Ricardo Della. Em pronunciamento, Bolsonaro critica fechamento de escolas, ataca governadores e culpa mídia. Folha de S. Paulo, 24 de março de 2020. Disponível em <https://www1.folha.uol.com.br/ poder/2020/03/em-pronunciamento-bolsonaro-critica-fechamento-de-escolas-ataca-governadores-e-culpa-midia. shtml(acessado em 15 de julho de 2020); Bolsonaro volta a atacar isolamento social e a defender retomada das atividades econômicas. Jornal Nacional. Disponível em <https://g1.globo.com/jornal-nacional/noticia/2020/05/14/ bolsonaro-volta-a-atacar-isolamento-social-e-a-defender-retomada-das-atividades-economicas.ghtml > (acessado em 15 de julho de 2020) 
tese de que a fome pela paralisação da economia mataria tanto quanto a doença, dispondo as pessoas contra a ciência e abrindo espaço para a contestação da necessidade da adoção do conjunto de medidas já implementadas em outros países e que governadores e prefeitos buscavam implementar no Brasil. ${ }^{21}$ Essas medidas visavam, por um lado, controlar o ritmo do contágio pelo vírus para evitar a sobrecarga do sistema de saúde e, por outro, evitar a completa deterioração das condições de vida e de retomada da atividade econômica passada a fase aguda da pandemia.

Formulando o problema em termos arendtianos, a propagação de mentiras, desinformação e distorção do debate, com consequências potencialmente mortais, diz respeito à relação entre opinião e conhecimento, verdade e mentira. O conhecimento científico sobre o vírus e a doença é produzido enquanto ela evolui ao redor do mundo, ou seja, em locais diferentes, o que lhe imprime um caráter contingente. Mas, nesse caso, a contingência concorre para desestabilizar uma imagem comum da ciência como instância de verdades, se não perenes, ao menos duradouras. Essa desestabilização tem se mostrado importante no Brasil, um país em que o próprio processo de produção científica é desconhecido da maioria da população. Ela facilita aos interessados, se não desacreditar a ciência e outros especialistas, cuja autoridade repousa em conhecimento técnico, no mínimo igualar o సิำ que falam sobre a doença e a pandemia à opinião de não especialistas.

\&े Como assinalamos na seção anterior, \& Arendt (1994b) fez um esforço por caracterizar İ o espaço público como domínio das opiniões e $\dot{2}$ por criticar o que poderíamos considerar uma 今 hybris da racionalidade científica (Arendt, 1998); mas a positividade das opiniões, para ela, não implica negligenciar o papel do conhecimento no debate público ou igualar co-

${ }^{21}$ FRAGA, Armínio. Covid-19: primeiras lições, desafios e propostas. Folha de S. Paulo, 29 de março de 2020. Disponível em <https://www1.folha.uol.com.br/colunas/ arminio-fraga/2020/03/covid-19-primeiras-licoes-desafios-e-propostas.shtml > (acessado em 14 de julho de 2020). nhecimento científico e opiniões arbitrárias. Arendt não abre mão da distinção, e a aborda criticamente, ou seja, fornece elementos para entendermos que o conhecimento científico deve informar as opiniões, tendo papel importante para a qualidade das trocas, da deliberação no espaço público, em especial no mundo moderno, em que o debate tem por objeto questões complexas.

Pensando com ela, o papel do conhecimento é, contudo, instrumental, ou seja, ele deve estar a serviço do público. É certo que, para que esse papel chegue a se cumprir, é preciso que o conhecimento seja compreensível, isto é, tenha sentido para pessoas comuns e importância no mundo. A condição humana tem a técnica e a ciência como objeto de preocupação. Em 1958, elas já eram mais presentes e potentes do que nunca, a ponto de se poder produzir a vida em laboratório e lançar satélites ao espaço, e também já eram inacessíveis a leigos, pois, segundo Arendt (1998), cientistas se moviam cada vez mais em um mundo sem discurso e, portanto, ou rigorosamente sem sentido ou de sentido incomum, isto é, compartilhado apenas entre especialistas e distante do senso comum. A popularidade de divulgadores científicos, que aparecem no debate público como organizadores do conhecimento acumulado sobre a doença e mediadores empenhados em levar esse conhecimento a audiências de não especialistas, faz pensar no diagnóstico de Arendt. Empiricamente, a circulação de informações falsas sobre a doença, o contágio e seus efeitos podem ser pensados considerando uma série de fatores: (i) a forma científica que seus autores lhes imprimiram, facilitando o reconhecimento do que comunicavam e a eficácia de sua palavra; (ii) a oferta abundante de certezas; (iii) o aceno com saídas fáceis e imediatas para uma situação difícil compreensão e que interrompe a rotina da vida, a vida habitual. Como vimos no caso da cloroquina, remédio prescrito para malária e para artrite reumatoide, mas que teria tido eficácia comprovada contra a Covid-19 em 
estudo rapidamente contestado, a publicação de um único artigo, sem os rigores e o tempo próprio da ciência, é usada para invalidar todo o conhecimento científico e para validar políticas convenientes, que compreendem desde a fabricação e a prescrição do medicamento de ineficácia comprovada até a reabertura de estabelecimentos comerciais ainda na ascendente da pandemia no país. Grandes veículos de comunicação, como o canal de TV por assinatura GloboNews, ${ }^{22}$ deram espaço a adeptos de notícias falsas em nome da pluralidade de perspectivas na democracia. Em contrapartida, programas como o Jornal Nacional, tradicional e de larga audiência, trabalham para estabelecer os fatos básicos acerca da pandemia, recuperando falas do presidente, e para retratar dramas e mortos, dando espaço a suas histórias, projetando sua imagem ao fundo da bancada dos apresentadores. ${ }^{23}$ Com isso, contribuem para conter o descrédito nos próprios sentidos em que mentiras e falsificações os lançam (o que é especialmente perigoso em um momento em que não se podem ajustá-los em interações face-a-face), dão dimensão visível e audível à tragédia, e permitem que ela se projete na cena nacional.

Um dos ganhos de pensar a situação com Arendt é recuperar para a discussão a dimensão normativa da pluralidade e compreender sua importância para o espaço público contemporaneamente. Em outras palavras, a pluralidade é condição para a ação, mas deve ser pautada pela constante crítica e publicidade dos argumentos. No limite, ela pressupõe um compromisso com a opinião verdadeira e o afastamento da palavra proferida unicamente para seduzir e enganar.

${ }^{22}$ G1. Luiz Mandetta, Osmar Terra e Humberto Costa discutem agravamento da pandemia. Disponível em <https:// g1.globo.com/globonews/globonews-debate/playlist/videos-luiz-mandetta-osmar-terra-e-humberto-costa-discutem-agravamento-da-pandemia.ghtml $>$ (acessado em 14 de julho de 2020).

${ }^{23}$ Redação. William Bonner anuncia 'novo cenário’ do JN em homenagem aos mortos pelo coronavírus. Notícias da TV, 14 de maio de 2020. Disponível em < https://noticiasdatv.uol.com.br/noticia/televisao/william-bonner-anuncia-novo-cenario-do-jn-para-homenagear-mortos-pelo-coronavirus-36806 $>$ (acessado em 15 de julho de 2020).

\section{CONSIDERAÇÕES FINAIS}

Este artigo se dispôs a pensar a pandemia de Covid-19, em especial seu impacto sobre o espaço público, com Hannah Arendt. Para tanto, reconstruímos a ideia arendtiana de espaço público, tal como ela é apresentada em $A$ condição humana, assinalando seus contornos, suas possibilidades e seus limites. Um ganho analítico que o pensamento arendtiano nos oferece é a possibilidade de pensar o público ligado a práticas sociais, sem abrir mão de uma dimensão normativa. Ele nos possibilita, em suma, analisar fenômenos sociais em curso e nos ajuda a julgar o que está diante dos nossos olhos desde uma perspectiva situada, a ser alargada pelo esforço por incorporar outros pontos de vista, reais ou imaginados (Arendt, 1992), ao nosso próprio.

No que se refere à pandemia, esse ganho é real porque, como tentamos mostrar na seção anterior, um dos efeitos do fenômeno foi propiciar a formação de públicos a partir de casa, o que desafia a rígida separação arendtiana desses espaços, mas também chama a atenção para a espontaneidade e os trabalhos da imaginação em sua construção. Esses públicos se mostraram contingentes, mas seu registro em imagens sugere que eles importaram para quebrar o isolamento decorrente das políticas sanitárias. A circulação de seus registros faz pensar que o público pode ser criado a partir de práticas que se ancoram naquilo que compartilhamos, como repertórios musicais, e que possibilitam criar novos comuns. Na pandemia, o privado e o público aparecem, assim, ligados aos usos que fazemos de certos espaços físicos, e esses usos podem ser transformadores, o que faz pensar que os sentidos desses espaços são produzidos na prática, nas próprias interações das pessoas umas com as outras.

Com a pandemia se evidencia, ademais, uma mudança nos assuntos em debate no espaço público, ou seja, uma mudança de prioridades imediatas, e isso em escala global. Questões materiais se deslocam das margens para o centro da política, sendo enquadradas ora como 
questão de igualdade, ora como questão de pobreza, vulnerabilidade ou precariedade. No cerne do debate se colocam formas de transferência direta de renda. É claro que essa questão encerra aspectos técnicos intrincados; o que nos interessa aqui, contudo, é que ela emerge na pandemia como uma questão política por excelência. Pensando com Arendt, podemos entender, de um lado, que se trata, então, de uma tomada do espaço da política pela questão social, e de outro que não há incongruência entre sua transformação numa questão política e o pensamento arendtiano porque, como dissemos, a política, para Arendt (2018b), requer um julgamento livre de interesses privados, imparcial no sentido de particularmente desinteressado, e isso demanda o que ela chamou de liberação dos constrangimentos impostos pelas necessidades vitais. Nessa discussão, importa ter em conta que, ao relacionar julgamento imparcial e política, no registro do republicanismo, Arendt (2018b) não está afirmando que os pobres não possam julgar desinteressadamente, nem que os ricos não julguem tendo em vista interesses particulares, mas sim que é ilegítimo esperar que os pobres não sintam o peso da fome na formação dos seus juízos e que ancorar materialmente sua cidadania pode ser uma forma de controle político sobre os ricos e a captura do Estado. Uma medida como essa, de provisão de recursos suficientes para a participação despreocupada na política, é orientada, enfim, por ชิ um horizonte de universalidade - a cidadania-, o mas resultaria em uma ampliação da pluralida-

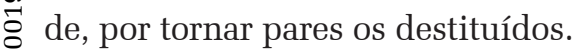

Esse processo esbarra, contudo, na imơ plantação da racionalidade instrumental no es¿. paço público, na produção e na circulação de ळ notícias falsas, que correm por circuitos sociais

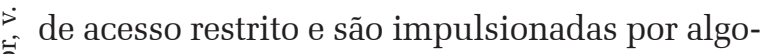
ritmos, os quais operam segundo determinados modelos de negócio. No limite, uma racionalidade instrumental tem se mostrado capaz de produzir um simulacro de aleatoriedade, de espontaneidade, que tem contribuído para constituir públicos blindados contra o choque do real e a contestação de crenças, preconceitos, dogmas, valores e mesmo ideias: ela abre, em síntese, a possibilidade de que nesses circuitos ganhem adesão narrativas descoladas do mundo. Nessa hipótese, a multiplicação de manifestações individuais parece dar materialidade e com isso emprestar credibilidade a falsificações dos fatos e mesmo do conhecimento, o que pensando com Arendt significa minar as condições de possibilidade das opiniões e, por conseguinte, do debate e da política. Para pensar esses públicos é importante considerar, assim, o que nos parece ser uma dimensão normativa do pensamento arendtiano, a saber, sua relação com a pluralidade, ou, ainda mais especificamente, a igualdade e a diferença. Levando essa dimensão a sério, no caso dos públicos constituídos a partir da circulação de mentiras e notícias falsas, não estaríamos diante de um público em sentido arendtiano, que está calcado na diferença de perspectivas, um reflexo do modo único pelo qual o mundo se abre a cada um, e sim diante de práticas de destruição do mundo, violentas: no caso da pandemia, tendo como consequência mortes em massa.

No contexto contemporâneo, marcado por um mundo em compasso de espera por remédios ou vacinas capazes de dar cabo da pandemia, repensar as categorias de Hannah Arendt é instigante. Dados o rápido desenvolvimento da ciência e da tecnologia, bem como a intensa colaboração entre os cientistas de todo o mundo, cabe imaginar que uma vacina venha a ser encontrada. Porém, como a própria reflexão de $A$ condição humana nos mostra, trata-se de uma possibilidade, mantendo-se o futuro em aberto e, portanto, em disputa.

Na disputa pela construção do mundo que não é ainda, concorrem as assimetrias dentro e fora dos países, as possibilidades abertas ao autoritarismo, mas também à associação e à introdução de novos começos. Em qualquer hipótese, a experiência compartilhada, vivida de forma inédita e sincrônica pelas sociedades de todo o planeta, revela a inafastável interdependência humana. Ameaçados por um inimi- 
go comum e externo à raça humana, o vírus, os indivíduos se viram vulneráveis. Isolados forçadamente em espaços privados, precisaram se reconectar por meio das tecnologias virtuais no desempenho das múltiplas dimensões da vida, do trabalho, dos afetos, da arte, do lazer e da política. De casa, buscaram reconstruir mundos, sobretudo em ambientes digitais. Embora se procure reproduzir nesses espaços as interações que se tem em espaços físicos de sociabilidade, o que vemos são processos de remodelagem, nos quais tanto os indivíduos se conectam por afinidades de ideias, agendas ou identidades, quanto se multiplicam opiniões à semelhança umas das outras. Ou seja, tanto se criam pontes quanto se formam 'bolhas'.

Com a releitura de $A$ condição humana sessenta anos depois de sua publicação, podemos perceber a atualidade do princípio normativo da pluralidade e da intersubjetividade como cernes da ação política. No terremoto causado pela pandemia, esse princípio se afirma, tornando mais urgente a construção de diálogos e pontes para que saídas coletivas possam ser pensadas. Os temas de formas de transferências diretas de renda e do lugar da ciência nas democracias têm constituído conteúdos privilegiados desses diálogos.

Recebido para publicação em 16 de julho de 2020 Aceito em 15 de outubro de 2020

\section{REFERÊNCIAS}

ARENDT, Hannah. Lying in politics. In: Crises of the Republic. San Diego-New York-London: Harcourt Brace \& Company, 1972.

. The origins of totalitarianism. San DiegoNew York-London: Harcourt Brace \& Company, 1973.

ARENDT, Hannah-. The life of the mind. San Diego-New York-London: Harcourt, 1978.

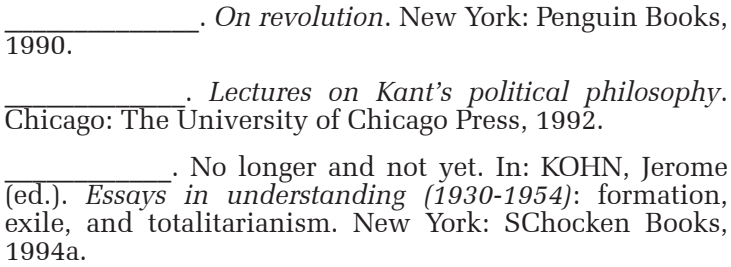

. No longer and not yet. In: KOHN, Jerome (ed.). Essays in understanding (1930-1954): formation, exile, and totalitarianism. New York: SChocken Books, 1994a.

Understanding and politics. In: KOHN, Jerome (ed.). Essays in understanding (1930-1954): formation, exile, and totalitarianism. New York: SChocken Books, 1994b.

Philosophy and politics. In: KOHN, Jerome (ed.). Essays in understanding (1930-1954): formation, exile, and totalitarianism. New York: SChocken Books, 1994c.

The human condition. 2nd ed. ChicagoLondon: The University of Chicago Press, 1998.

Introduction into politics. In: KOHN, Jerome (ed.). The promise of politics. New York: Schocken Books, 2005, p. 93-200.

Entre o passado e o futuro. Tradução de Mauro W. Barbosa. São Paulo: Perspectiva, 2016.

"The freedom to be free": the conditions and meaning of revolution. In: KOHN, Jerome (ed.). Thinking without a banister: essays in understanding 1953-1975. New York: Schocken Books, 2018a.

Public rights and private interests: a response to Charles Frankel. In: KOHN, Jerome (ed.). Thinking without a banister: essays in understanding 1953-1975. New York: Schocken Books, 2018b.

BENHABIB, Seyla. Feminist theory and Hannah Arendt's concept of public space. History of the Human Sciences, v. 6, n. 2, 1993, p. 97-114.

The reluctant modernism of Hannah Arendt. Laham: Rowman \& Littlefield, 2003.

BERNSTEIN, Richard. Rethinking the social and the political. In: Philosophical profiles: essays in a pragmatic mode. Philadelphia: University of Pennsylvania Press, 1986, p. 238-259.

BUTLER, Judith. Notes toward a performative theory of assembly. Cambridge, Mass.-London: Harvard University Press, 2015

CANOVAN, Margaret. A case of distorted communication: a note on Habermas and Arendt. PoliticalTheory, v. II, n. 1, February 1983, p. 105-116.

ELSTER, 1999. The market and the forum: three varieties of political theory. In: James Bohman and William Regh (eds). Deliberative democracy. Cambridge: The MIT Press, 1997.

HABERMAS, Jürgen. O conceito de poder de Hannah Arendt. In: Barbara Freitag e Sergio Paulo Rouanet (orgs). Habermas. São Paulo: Ática, 1980.

The theory of communicative action. Vol. II. Translated by Thomas McCarthy. Boston: Beacon Press, 1989.

Direito e democracia: entre facticidade e validade. Rio de Janeiro: Tempo Brasileiro, v. II, 1997.

Mudança estrutural da esfera pública. Tradução de Denilson Luis Werle. São Paulo: Unesp, 2013. LUBENOW, Jorge Adriano. A categoria de esfera publica em Jurgen Habermas. 2007. 257p. Tese (doutorado) Universidade Estadual de Campinas, Instituto de Filosofia e Ciencias Humanas, Campinas, SP. Disponível em: < http:// www.repositorio.unicamp.br/handle/REPOSIP/280634>. Acesso em: 8 mar. 2020

VOLLRATH, Ernst; FANTEL, Hans. Hannah Arendt and the method of political thinking. Social Research, v. 44, n. 1, 1977, p. 160-182.

YOUNG, Iris Marion. Justice and the politics of difference. Princeton: Princeton University Press, 1990. 


\section{RETHINKING THE PUBLIC SPACE IN PANDEMIC TIMES: Hannah Arendt, 60 years after the publication of The human condition}

\author{
Renata Nagamine \\ Denise Vitale
}

This paper analysis Hannah Arendt's concept of public space, as presented on The human condition, drawing on the COVID-19 pandemic. The paper focuses on this experience, which invites us to think about the reconfigurations on space (and time), looking at the emptiness of the cities, the haltof economy, the circulation of fake news and the strength of certain kinds of interactions. Arendt offers good arguments to think the pandemic challenges.

Key-Words: Vita Activa. Public Space. Plurality. Pandemic. Political Theory.

\section{REPENSER L'ESPACE PUBLIC EN TEMPS PANDÉMIQUE: Hannah Arendt, 60 ans après $L a$ condition humaine}

\author{
Renata Nagamine \\ Denise Vitale
}

Cet essai réfléchit sur l'idée d'espace public dans la pensée d'Hannah Arendt telle que présentée dans La condition de l'homme moderne. Nous allons reprendre les concepts d'Arendt en élaborant sur La pandémie de Covid-19, 2020. L'essai prend la pandémie comme une experience qui invite à réfléchir aux reconfigurations de l'espace (et du temps) enregardant le vidage des villes, la paralysie de l'économie, la circulation de fake news et la redynamisation de certaines formes d'interaction. Nous comprenons que Arendt fournit des elements pour réfléchir aux défis posés par lapandémie et pour imaginer le passage du monde qu'il n'est plus au monde qui n'est pas encore.

Mots CLÉs: Vita activa. Space public. Pluralité; Pandémie. Theorie politique.

Denise Vitale - Doutora em Direito pela Universidade de São Paulo. Professora do Instituto de Humanidades, Artes e Ciências prof. Milton Santos da Universidade Federal da Bahia. Coordenadora do Programa de Pós-Graduação em Relações Internacionais da Universidade Federal da Bahia. Pesquisadora do CNPQ (PQ2). Integra os Grupos de Pesquisa Laboratório de Análise Política Mundial e Território, Poder e Desigualdades Sociais, desenvolvendo pesquisas na área de direitos humanos, meio ambiente, democracia e gênero. Suas mais recentes publicações são as co-organizações das coletâneas Gênero, Direito e Relações Internacionais, em parceria com Renata Nagamine e Dicionário Temático Desenvolvimento e Questão Social, coordenado por Anete Ivo.

Renata R. V. K. Nagamine - Doutora ou Mestre em direito internacional pela Faculdade de Direito da USP. Professora do Programa de Pós-Graduação em Relações Internacionais da. Universidade Federal da Bahia, colabora em pesquisa no Centro Brasileiro de Análise e Planejamento (Cebrap), desenvolvendo pesquisas na área de religião e espaço público. 